\title{
Sleep Quality among Medical Students of a Tertiary Care Hospital: A Descriptive Cross-sectional Study
}

\author{
Nabin Sundas, ${ }^{1}$ Saransh Ghimire, ${ }^{1}$ Suzit Bhusal, ${ }^{1}$ Rakshya Pandey, ${ }^{1}$ Krishna Rana, ${ }^{2}$ Hemang Dixit ${ }^{1}$ \\ 'Kathmandu Medical College, Sinamagal, Kathmandu, Nepal ${ }^{2}$ Deurali Primary Health center, Nuwakot, Nepal.
}

\section{ABSTRACT}

Introduction: Medical students are under constant stress due to demanding academic load, fear of exam failure and hectic schedules. These factors can lead to poor sleep quality among medical students. Sleep quality of medical students not only determine their academic performance but is also important in determining long term effect on cognitive, psychosocial, behavioural as well as physical health of individuals. Although there are not enough recent studies to assess sleep quality of students, it is necessary to evaluate the condition of sleep among students. This study aims to find out the prevalence of poor sleep quality among medical students.

Methods: This descriptive cross-sectional was conducted among undergraduate medical students of Kathmandu Medical College from October to November 2019 after taking ethical clearance from Institutional Review Committee of a tertiary care hospital before collecting data from participants. Subjects were recruited by simple random sampling from students of first, second, third and final years and were asked to fill the self-reported questionnaires, using Pittsburgh Sleep Quality Index. Descriptive statistical analysis was done using Statistical Software for Social Sciences version 24.

Results: Out of 217 selected medical students, 96 (44.23\%) of students have poor sleep quality with prevalence among male and female students as $41(39.8 \%)$ and $55(48.2 \%)$ respectively. The mean duration of sleep among students was $6.7 \pm 1.6$ hours.

Conclusions: Significant numbers of medical students have poor sleep quality which may affect their academic performance and may have long term impact on their health. Efforts must be directed towards educating about the sleep hygiene as well as proper time management skills.

Keywords: medical students; Pittsburgh sleep quality index; sleep quality.

\section{INTRODUCTION}

Medical students are especially vulnerable to poor sleep quality. ${ }^{1}$ Sleep related disorders are prevalent in high number among medical students throughout the world. $^{2,3}$ Sleep is a very important parameter for the consolidation memories and that being sleep deprived reduces one's ability to learn. ${ }^{4}$ Quality of sleep can be categorized into subjective and objective aspects. ${ }^{5}$

Prevalence of poor sleep quality is higher among undergraduate medical students compared to students from other fields. ${ }^{1}$ Poor sleep quality effects academic performance and also effects intelligence and cognitive functions which is key for medical professionals. ${ }^{6}$ In Nepal, medical students have poorer attitude of sleep hygiene. ${ }^{7}$ Considering the consequences and prevalence

Correspondence: Nabin Sundas, Kathmandu Medical College, Sinamangal, Kathmandu, Nepal. Email: Nabinsundas2@gmail.com, Phone: $+977-9803462143$. 
of the problem, it is essential to determine quality of sleep among medical students.

This study aims to find the prevalence of poor sleep quality among medical students of Kathmandu Medical College.

\section{METHODS}

A descriptive cross-sectional study was done on undergraduate medical students of Kathmandu Medical College (KMC) from October to November 2019. Ethical clearance was obtained from Institutional Review Committee (IRC) of Kathmandu Medical College before collecting data from participants. List of all the medical students who were present at the duration of study was obtained from college administration and consecutive number was given to the list. Simple random sampling technique was applied by using Random table to select study participants. Those students who were absent from regular classes for at least a month as well as interns were excluded from the study.

Sample size was calculated as:

$$
\begin{aligned}
& n=z^{2} \times(p \times q) / e^{2} \\
& =1.96^{2} \times(0.5 \times 0.5) /(0.05)^{2} \\
& =384
\end{aligned}
$$

Where,

$\mathrm{n}=$ Sample size

$\mathrm{z}=1.96$ at $95 \% \mathrm{Cl}$

$\mathrm{p}=$ prevalence of poor sleep quality among medical students $(50 \%)$

$q=1-p$

$\mathrm{e}=$ margin of error, $5 \%$

Adjusted sample size

$=\mathrm{n} /(1+((\mathrm{n}-1) / \mathrm{N}))$

$=207$

Where, $\mathrm{N}=$ Target population $=450$

Therefore, the calculated samples size was 207 and considering $5 \%$ of non-response rate the sample size taken was 217 .

All the respondents were informed about the aim and objectives of the study and informed consent was taken prior to study and they were aware that their participation was voluntary. Confidentiality of participants were ensured. Students were asked to fill up self-reporting questionnaire using Pittsburgh Sleep Quality Index (PSQI). ${ }^{8}$ Descriptive statistical analysis was done using Statistical Software for Social Sciences (SPSS) version 24 .

\section{RESULTS}

The prevalence of poor sleep quality among medical students was found to be $96(44.23 \%)$ with Global PSQI score of more than 5 . Out of 217 participants, $107(47.5 \%)$ were male and $114(52.5 \%)$ were female, among them 55 (25.3\%), $36(16.6 \%), 60$ (27.6\%) and $66(30.4 \%)$ were studying in first, second, third and final year respectively. The average age of students was $21.39 \pm 1.6$ years. Among male students, the prevalence of poor sleep quality was 41 (39.8\%) which is lesser than female students with prevalence of 50 (48.2\%) (Table 1).

\begin{tabular}{|llc|}
\hline \multicolumn{3}{|l|}{$\begin{array}{l}\text { Table } 1 . \text { Sleep Quality Variation in Gender and } \\
\text { Years of study. }\end{array}$} \\
\hline $\begin{array}{l}\text { Sermal } \\
\text { sleepers }\end{array}$ & Poor sleepers \\
Male & $62(60.2 \%)$ & $41(39.8 \%)$ \\
Female & $59(51.8 \%)$ & $55(48.2 \%)$ \\
Year of study & $32(58.2 \%)$ & $23(41.8 \%)$ \\
First & $28(77.8 \%)$ & $8(22.2 \%)$ \\
Second & $28(46.7 \%)$ & $32(53.3 \%)$ \\
Third & $33(50 \%)$ & $33(50 \%)$ \\
Fourth & & \\
\hline
\end{tabular}

Poorer sleep quality is observed among the medical student staying at hostel $57(47.9 \%)$ than those who doesn't stay at hostel 39 (39.8\%) (Table 2).

Table 2. Comparison of students who staying and not staying at hostel.

\begin{tabular}{lll}
$\begin{array}{l}\text { Staying in } \\
\text { Hostel }\end{array}$ & Normal sleepers & Poor sleepers \\
Yes & $62(52.10 \%)$ & $57(47.9 \%)$ \\
No & $59(60.20 \%)$ & $39(39.8 \%)$ \\
\hline
\end{tabular}

The average duration of sleep among students was $6.7 \pm 1.6$ hours (Table 3 ).

Table 3. Sleep Duration.

\begin{tabular}{ll|} 
Sleep duration & No. of students \\
More than 7 hours & $78(35.9 \%)$ \\
$6-7$ hours & $93(42.9 \%)$ \\
$5-6$ hours & $33(15.2 \%)$ \\
Less than 5 hours & $13(6 \%)$ \\
\hline
\end{tabular}


Out of 217 students, 204 (94\%) did not use sleep medications in the past one month whereas $13(6 \%)$ used sleep medications at least once in the past one month. When students were asked that how much it took them to fall asleep, $137(63.1 \%)$ students respond that it took less than 15 minutes whereas 80 (36.8\%) respond it took them more than 15 minutes to fall asleep. Subjective sleep quality of most of the student 102 (47\%) have fairly good sleep quality (Figure 1).

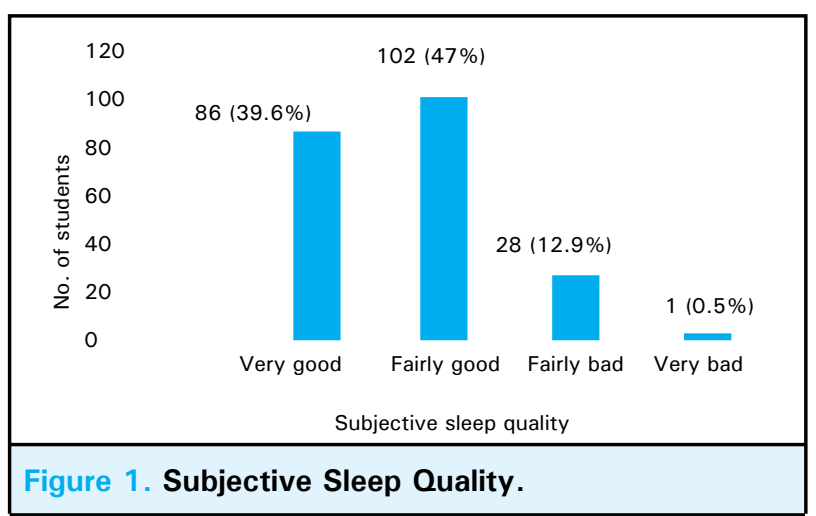

\section{DISCUSSION}

Prevalence of poor sleep quality among students in our study is found to be $44 \%$ which was higher than a previous study done among college students using the same PSQI questionnaire is $35.4 \%$ though the study was conducted among undergraduate students nonmedical study. ${ }^{9}$ The cause of poor sleep quality among medical students can be attributed to hectic schedule in medical college and increased academic load. Similar study done on medical student of Karachi, Pakistan showed prevalence of poor sleep quality of $39.5 \%$, more prevalent female poor sleepers $44 \%$ than male $32.8 \%$ which is almost similar to our study. ${ }^{10}$

Sleep quality was poorer among students studying in clinical sciences (third and fourth year) in comparison to those studying in basic sciences (first and second year) may be due to comparatively more hectic schedules due to clinical rotations in clinical sciences in contrast to the study by Camila de Castro Corrêa et al. in which sleep quality is poorer in first and second year than third, fourth, fifth and sixth year. ${ }^{11}$ Poor sleep quality was found to be more prevalent among students staying in hostel rather than those stayed at home. This variation can be explained by late night social gatherings in the hostel as well as increased participation in extracurricular activities.

Our study was carried using a self-reporting questionnaire which is not quantitative assessment of sleep quality. Accurate assessment of sleep quality requires extensive tests such as polysomnography.

This study was conducted a single institution so, the findings of this study cannot be generalized and more studies at other medical institutions are required to find out actual prevalence of poor sleep among medical students.

\section{CONCLUSIONS}

Every two out of five medical students found to have poor sleep quality which not only affecting their academic performance but also effect their physical health. This suggest the need of measures to identity the students at risk and educating medical students about proper sleep hygiene and the consequences of poor sleep practices.

\section{ACKNOWLEDGEMENTS}

We heartily acknowledge to all the medical students of Kathmandu Medical College who participate in this study.

Conflict of Interest: None.

\section{REFERENCES}

1. Wong JG, Patil NG, Beh SL, Cheung EP, Wong V, Chan LC, et al. Cultivating psychological well-being in Hong Kong's future doctors. Medical teacher. 2005;27(8):715-9. [P PubMed [ Full Text]

2. Cheng SH, Shih CC, Lee IH, Hou YW, Chen KC, Chen KT, et al. A study on the sleep quality of incoming university students. Psychiatry Res. 2012;197(3):270-4. [PubMed | DOI]
3. Manzar MD, Zannat W, Kaur M, Hussain ME. Sleep in university students across years of university education and gender influences. International journal of adolescent medicine and health. 2015;27(3):341-8. [Full Text]

4. Frank MG, Benington JH. The Role of Sleep in Memory Consolidation and Brain Plasticity: Dream or Reality? The Neuroscientist. 2006;12(6):477-88. [ubMed | DOI] 
5. Akerstedt T, Kecklund G, Axelsson JJS-SuS. Subjective and objective quality of sleep. Somnologie. 2008;12(2):104. [Full Text]

6. Killgore WD, Kahn-Greene ET, Lipizzi EL, Newman RA, Kamimori GH, Balkin TJ. Sleep deprivation reduces perceived emotional intelligence and constructive thinking skills. Sleep medicine. 2008;9(5):517-26. [PubMed | DOI]

7. Shankar P.R. Knowledge, Attitude and Behaviour Towards Sleep Among Fourth Semester Medical Undergraduates in Pokhara, Nepal. Journal of Clinical and Diagnostic Research. 2008;2(5):1074-80. [Full Text]

8. Buysse DJ, Reynolds CF, 3rd, Monk TH, Berman SR, Kupfer DJ. The Pittsburgh Sleep Quality Index: a new instrument for psychiatric practice and research. Psychiatry Res. 1989;28(2):193-213. [ubMed | DOI]
9. Bhandari PM, Neupane D, Rijal S, Thapa K, Mishra SR, Poudyal AKJBP. Sleep quality, internet addiction and depressive symptoms among undergraduate students in Nepal. BMC Pyschiatry. 2017;17(1):106. [PubMed | Full Text | DOI]

10. Surani AA, Zahid S, Surani A, Ali S, Mubeen M, Khan RH. Sleep quality among medical students of Karachi, Pakistan. Pak Med Assoc. 2015 Apr;65(4):380-2. [uㅣㄹed | Full Text]

11. Corrêa CC, Oliveira FK, Pizzamiglio DS, Ortolan EVP, Weber SAT. Sleep quality in medical students: a comparison across the various phases of the medical course. J Bras Pneumol. 2017;43(4):285-9. [Full Text] 